\title{
Sterol Oxidation in Ready-to-Eat Infant Foods During Storage
}

\author{
Guadalupe García-Llatas, ${ }^{\dagger}$ Luisito Cercaci, ${ }^{*}$ \\ Maria Teresa Rodriguez-Estrada, ${ }^{*}{ }^{*}$ M. Jesús Lagarda, ${ }^{\dagger}$ Rosaura Farré, $^{\dagger}$ \\ AND GIOVANNI LERCKER \\ Área de Nutrición y Bromatología, Universitat de València, Avda. Vicent Andrés Estellés s/n, \\ 46100 Burjassot-Valencia, Spain and Dipartimento di Scienze degli Alimenti, Università di Bologna, \\ Viale G. Fanin, 40, 40127 Bologna, Italy
}

\begin{abstract}
The effect of storage on sterol oxidation of ready-to-eat infant foods was evaluated. Two different liquid infant foods (honey or fruits flavors), prepared with milk and cereals, were stored for 0, 2, 4, 7 and 9 months at $25^{\circ} \mathrm{C}$. Sterol oxidation products (SOP) were isolated by cold saponification, purified by silica solid-phase extraction, and analyzed by gas chromatography (GC) and GC-mass spectrometry. $\beta$-Sitosterol was the most representative sterol, followed by cholesterol and campesterol. No significant differences in the total and single SOP content $(0.8-1 \mathrm{mg} / \mathrm{kg}$ of product) were observed with respect to storage time and type of sample; the main SOP found was 7-ketositosterol $(<0.2$ $\mathrm{mg} / \mathrm{kg}$ of product). The extent of stigmasterol oxidation (2.9\%) was higher than that of cholesterol $(1.9 \%)$ and $\beta$-sitosterol $(1.4 \%)$. The type and quality of raw materials, as well as the processing conditions, seem to greatly influence SOP formation and accumulation in infant foods.
\end{abstract}

KEYWORDS: Sterol oxidation products; phytosterol oxidation products; infant foods; milk cereals; storage; trans fatty acids

\section{INTRODUCTION}

Sterols (cholesterol and phytosterols) are unsaturated molecules prone to oxidation, which can generate sterol oxidation products (SOP). Cholesterol and phytosterols are subjected to oxidation when exposed to air, which can be further enhanced by heating, ionizing radiation, chemical catalysts, fatty acid unsaturation level, and exposure to light. In general, oxidation of sterols is a free-radical chain reaction that begins with the formation of hydroperoxides, which may decompose into various compounds. The main oxidation products are hydroxy, keto, epoxy and triol derivatives. Enzymes, reactive oxygen species, and the photosensitizers may also induce lipid oxidation. Because oxidation can follow several reaction and isomerization mechanisms, a large number of different sterol oxides can be formed, many of which have already been identified (1).

Over the past few years, attention has been focused on the study and determination of cholesterol oxidation products (COP) rather than in phytosterol oxidation products (POP) (2), because of the asserted negative biological effects of COP (3-5). On the other hand, data and methods for the evaluation of POP concentration levels in food products of mixed origin are scarce, due to the inherent complexity of the analytical determination.

* To whom correspondence should be addressed. Telephone: +39 051-2096011, fax: +39-051-2096017, e-mail: maria.rodriguez@unibo.it.

$\dagger$ Universitat de València.

* Università di Bologna.
POP have been mostly analyzed in frying oils, fried products, margarines, bakery products, cereal-based foods, infant formulas, coffee, and biological samples (6-11). However, interest in POP has increased as a result of food supplementation with phytosterols and phytosterols esters because of their blood cholesterollowering effect (12). Although some studies have recently shown POP absorption from diet, results on their potential biological effects are still scarce and sometimes contradictory (13-16).

Most infant foods contain sterols from both vegetable and animal sources. The preparation of these food products involve heating and drying cycles that require elevated temperatures, often in the presence of oxygen. In addition, during storage, the contact with air and/or light and high temperatures could further enhance fatty acid and sterol oxidation. SOP have been found in infant milk formulas and milk cereals $(6,17-19)$, and meat- and fish-based infant foods $(20,21)$; the main SOP were 7-ketositosterol and 7-ketocholesterol. These milk and cerealbased baby foods are largely consumed during infancy and could, thus, be potentially harmful for children health.

The aim of this study was to evaluate the oxidative stability of sterols in two types of ready-to-eat milk and cereal-based infant food during storage, as related to their fatty acid composition. To the authors' knowledge, this is the first time that the different classes of sterol oxidation derivatives have been quantified in liquid infant foods, thus providing a more complete picture of their oxidation status. A validated gas chromatography (GC) method (10) was applied for this scope. 


\section{MATERIALS AND METHODS}

Reagents. Chloroform (p.a.), $n$-hexane (p.a.), methanol (Lichrosolv), diethyl ether, anhydrous sodium sulfate, potassium chloride, potassium hydroxide, and silica-gel thin-layer chromatography (TLC) plates (20 $\mathrm{cm} \times 20 \mathrm{~cm} \times 0.25 \mathrm{~mm}$ film thickness), were supplied by Merck (Darmstadt, Germany). Acetone (AnalaR) was purchased from BDH (VWR International Ltd., Leicestershire, UK). Double distilled water, $2^{\prime}, 7^{\prime}$-dichlorofluorescein (sodium salt), silver nitrate, and silylating agents (pyridine, hexamethyldisilazane, and trimethylchlorosilane), were supplied by Carlo Erba (Milano, Italy). ( $24 R$ )-Ethylcholest-5-en-3 $\beta$ ol $(\beta$-sitosterol, purity: 60\% $\beta$-sitosterol and 30\% (24R)-methylcholest5 -en-3 $\beta$-ol (campesterol)) was purchased from Research Plus (Bayonne, New Jersey). (24 $S$ )-methylcholest-5,22-dien-3 $\beta$-ol (brassicasterol, purity: 99\%), cholest-5-en-3 $\beta, 7 \alpha$-diol ( $7 \alpha$-hydroxycholesterol, purity: 99\%) and (24 S)-ethylcholest-5,22-dien-3 $\beta$-ol-7-one (7-ketostigmasterol, purity: 99\%) were supplied by Steraloids (Newport, Rhode Island). (24 $S)$-Ethylcholest-5,22-dien-3 $\beta$-ol (stigmasterol, purity: 93\%), cholest5-en-3 $\beta$-ol-7-one (7-ketocholesterol, purity: $99 \%$ ), cholest-5-en-3 $\beta$-ol (cholesterol, purity: 99\%), cholest-5-en-3 $\beta, 7 \beta$-diol ( $7 \beta$-hydroxycholesterol, purity: 99\%), $5 \alpha, 6 \alpha$-epoxy-cholestan- $3 \beta$-ol ( $\alpha$-epoxycholesterol, purity: $87 \%), 5 \beta, 6 \beta$-epoxy-cholestan- $3 \beta$-ol ( $\beta$-epoxycholesterol, purity: $80 \%$ ), cholestan-3 $\beta, 5 \alpha, 6 \beta$-triol (cholestanetriol, purity: $99 \%$ ), cholesten-5-en-3 $\beta, 19$-diol (19-hydroxycholesterol, purity: 99\%), $5 \alpha$ cholestane (purity: 97\%), and tridecanoic acid methyl ester were purchased from Sigma (St. Louis, Missouri). The purity of the standards was determined by GC. A standard mixture of fatty acid methyl esters (GLC 463) was purchased from Nu-Chek (Elysian, Minnesota)

Silica solid phase extraction (SPE) cartridges (Supelclean LC-Si, $500 \mathrm{mg} / 3 \mathrm{~mL}$ ) from Supelco (Bellefonte, Pennsylvania) were used for SOP purification.

Samples. Two types of liquid infant foods were used for this study. They mainly contained skimmed milk (88\%), hydrolyzed 8-cereals flour (wheat, corn, rice, oat, barley, rye, sorghum, and millet) $(8.8 \%)$, and vegetable oils; they differed in their minor ingredients (honey, $0.9 \%$; LH) and fruits (banana, orange, and apple, 1.1\%; LF). The declared fat content of both products was $2.6 \%(\mathrm{w} / \mathrm{w})$. The products were supplied by the manufacturer (Hero España S.A.).

Both products were obtained by a preheating at $90{ }^{\circ} \mathrm{C}$ and a following ultra-high-temperature (UHT) sterilization. Infant foods were packed in a commercial $250 \mathrm{~mL}$ tetra brick in an air-free atmosphere and stored at $25{ }^{\circ} \mathrm{C}$ for 9 months. They were analyzed just after being produced (zero time) and after 2, 4, 7, and 9 months of storage.

For each infant food type and storage point, three bricks from the same batch were sampled.

Lipid Extraction. Lipids were extracted according to a modified version (22) of the method described by Folch et al. (23).

Preparation and GC Analysis of Total Fatty Acid Methyl Esters (FAME). Fatty acids (FA) were determined as suggested by Cercaci et al. (11). The limit of quantitation (LOQ) was $0.01 \mathrm{~g} / 100 \mathrm{~g}$ of FA.

Silver-Ion TLC-GC Analysis of Trans Fatty Acids (TFA). To accurately quantify the TFA isomers, silver-ion TLC-GC was performed according to Cercaci et al. (11). The LOQ was $0.01 \mathrm{~g} / 100 \mathrm{~g}$ of FA.

Isolation of Sterols and Sterol Oxides (SOP) (10). Sterols and SOP were isolated from about $600 \mathrm{mg}$ of lipid, which were extracted from $25 \mathrm{~g}$ of sample. For the determination of sterols, $1 / 10$ of the unsaponifiable matter was subjected to silylation (24), dried under nitrogen stream, and dissolved in $250 \mu \mathrm{L}$ of $n$-hexane; $1 \mu \mathrm{L}$ of the silylated sterols was injected into gas chromatograph-flame ionization detector (GC-FID) and gas chromatograph-mass spectrometry (GC-MS) for quantification and identification purposes, respectively.

Regarding the determination of the sterol oxides, the remaining $9 / 10$ of the unsaponifiable matter was divided into two portions and purified by silica SPE according to Guardiola et al. (25). SOP were eluted with acetone. The purified fraction was then silylated, dried under nitrogen stream, and dissolved in $40 \mu \mathrm{L}$ of $n$-hexane. A $1 \mu \mathrm{L}$ portion of the silylated sterols was injected into GC-FID and GC-MS under the same analytical conditions used for the determination of sterols.

To further confirm that there were no overlappings with peaks due to matrix interferences, the purified SOP fraction was separated by TLC
(10). The TLC bands of the oxide derivatives were scrapped off, extracted with diethyl ether, silylated, and injected into GC-FID and GC-MS.

GC-FID and GC-MS Analysis of Sterols and SOP. Quantification of sterols and SOP was performed by GC-FID. A Carlo Erba HRGC 5300 Mega Series (Rodano, Milan, Italy) was equipped with a split - splitless injector and a FID. A fused silica capillary column (50 $\mathrm{m} \times 0.25 \mathrm{~mm}$ i.d. $\times 0.25 \mu \mathrm{m}$ film thickness) coated with $5 \%$ phenyl-95\% dimethyl-polysiloxane (CP-Sil 8CB, Chrompack-Varian, Middelburg, The Netherlands) was used. The oven temperature was programmed from $280{ }^{\circ} \mathrm{C}$ (kept for $20 \mathrm{~min}$ ) to $290{ }^{\circ} \mathrm{C}$ at a rate of 0.2 ${ }^{\circ} \mathrm{C} / \mathrm{min}$ and held for $2 \mathrm{~min}$; the oven temperature was then raised to $320{ }^{\circ} \mathrm{C}$ at a rate of $30{ }^{\circ} \mathrm{C} / \mathrm{min}$ and held for $10 \mathrm{~min}$. The injector and detector temperatures were both set at $325^{\circ} \mathrm{C}$. Helium was used as a carrier gas at a flow rate of $2.6 \mathrm{~mL} / \mathrm{min}$; the split ratio was 1:20.

Identification of sterols and SOP was performed by GC-MS. An Agilent $6890 \mathrm{~N}$ GC coupled to a $5973 \mathrm{~N}$ mass-selective detector (Agilent Technologies, California) was used. The system was fitted with a capillary column $(30 \mathrm{~m} \times 0.25 \mathrm{~mm}$ i.d. $\times 0.25 \mu \mathrm{m}$ film thickness $)$ coated with 5\% phenyl-95\% dimethyl-polysiloxane (HP-5MSi, Agilent Technologies, California), and helium was used as carrier gas at a flow rate of $1 \mathrm{~mL} / \mathrm{min}$. The oven temperature was programmed to go from 250 to $310^{\circ} \mathrm{C}$ at $0.8^{\circ} \mathrm{C} / \mathrm{min}$. The injector and transfer line temperatures were set at 310 and $280{ }^{\circ} \mathrm{C}$, respectively. Manual injection of $1 \mu \mathrm{L}$ was performed in the split mode with a 1:10 split ratio. The filament emission current was $70 \mathrm{eV}$. A mass range from 40 to $650 \mathrm{~m} / \mathrm{z}$ was scanned at a rate of $1500 \mathrm{amu} / \mathrm{s}$.

Quantification and Identification of Sterols and SOP. Sterols and SOP were quantified by the internal standard method, using $5 \alpha-$ cholestane and 19-hydroxycholesterol as internal standards (IS), respectively. The GC-FID response factors of sterols and SOP with respect to their corresponding IS were considered equal to 1 . The LOQs of the GC-FID analysis of sterols and SOP were $0.1 \mathrm{mg} / 100 \mathrm{~g}$ of sample and $0.5 \mu \mathrm{g} / 100 \mathrm{~g}$ of sample, respectively, which were calculated at a signal-to-noise ratio equal to $6: 1$.

Identification of sterols was performed by comparing the retention time and mass spectra with those of the commercial sterol standards. SOP were identified by comparing their retention time and mass spectra with those of commercial COP and 7-ketostigmasterol standards, as well as with those of SOP synthesized as suggested by Conchillo et al. (10). The mass spectra of SOP were also compared with those reported in literature (7).

Data Analysis. One lipid extraction was carried out per sample. Each parameter was determined twice per each lipid extraction. GC data were stored and processed with a Turbochrom Navigator acquisition system (Ver. 6.1.1.0.0:K20, Perkin-Elmer Instruments, Norwalk, Connecticut). Mean and standard deviation data of the SOP contents determined in each sample are shown in Table 3. Statgraphics v. 3.1 (Rockville, Maryland) was used to perform two-way (sample type and storage time) analysis of variance (ANOVA) and Tukey's honest significant difference test (HSD) at a 95\% confidence level $(p<0.05)$ to identify differences among samples.

\section{RESULTS AND DISCUSSION}

To better understand the oxidative behavior of ready-to-eat infant foods, as well as to obtain more information about the quality and unsaturation degree of their lipid fraction, total FA composition of these food products was determined (Table 1). Because no significant differences were found between the FA composition of LH and LF, only the FA content of LH is reported. The most abundant FA was oleic acid, followed by linoleic, palmitic, lauric, myristic, and stearic acids. Unsaturated FA accounted for approximately $60 \%$ of total FA, resulting in a linoleic/ $\alpha$-linolenic ratio of 18.2, higher than the one suggested by the European Commission (EC) Directive for infant formulas $(5-15,26)$.

The total FA composition of the samples here analyzed displays a wide range of FA, which reflects the original composition of the raw materials and/or ingredients. Short-chain 
Table 1. Fatty Acid Composition (g/100 g of Lipids) of LH Sample ${ }^{a}$, FA classes ( $\mathrm{g} / 100 \mathrm{~g}$ of Lipids), and Their Ratios ${ }^{b}$

\begin{tabular}{|c|c|}
\hline fatty acid & $\mathrm{g} / 100 \mathrm{~g}$ of lipids \\
\hline C4:0 & $0.25(0.04)$ \\
\hline C6:0 & $0.17(0.02)$ \\
\hline $\mathrm{C} 7: 0$ & $0.07(0.00)$ \\
\hline $\mathrm{C} 8: 0$ & $1.63(0.08)$ \\
\hline C9:0 & $0.02(0.00)$ \\
\hline $\mathrm{C} 10: 0$ & $1.31(0.10)$ \\
\hline C12:0 & $10.52(0.62)$ \\
\hline C12:1 & $0.02(0.00)$ \\
\hline C14:0 & $4.40(0.00)$ \\
\hline C14:1 & $0.03(0.00)$ \\
\hline $\mathrm{C} 15: 0$ & $0.06(0.00)$ \\
\hline C16:0 & $18.55(1.06)$ \\
\hline C16:1t7 & $0.03(0.00)$ \\
\hline$\Sigma C 16: 1^{c}$ & $0.13(0.02)$ \\
\hline C17:0 & $0.05(0.00)$ \\
\hline C17:1 & $0.03(0.00)$ \\
\hline C18:0 & $3.20(0.01)$ \\
\hline$\Sigma \mathrm{C} 18: 1 t^{d}$ & $0.17(0.03)$ \\
\hline $\mathrm{C} 18: 1 c 9^{e}$ & $35.59(3.66)$ \\
\hline $\mathrm{C} 18: 1 \mathrm{C} 11^{f}$ & $0.84(0.04)$ \\
\hline$\Sigma C 18: 2 t^{g}$ & ND \\
\hline $\mathrm{C} 18: 2^{h}$ & $18.92(1.36)$ \\
\hline C20:0 & $0.27(0.00)$ \\
\hline$\Sigma \mathrm{C} 18: 3 t^{i}$ & ND \\
\hline $\mathrm{C} 18: 3^{j}$ & $1.04(0.07)$ \\
\hline C20:1 & $0.25(0.03)$ \\
\hline C22:0 & $0.35(0.02)$ \\
\hline C22:1 & $0.04(0.01)$ \\
\hline C24:0 & $0.13(0.02)$ \\
\hline SFA & 41.85 \\
\hline MUFA & 37.50 \\
\hline PUFA & 20.44 \\
\hline TFA & 0.20 \\
\hline PUFA/SFA & 0.49 \\
\hline$($ MUFA + PUFA)/SFA & 1.38 \\
\hline$(n-6) /(n-3)$ & 18.15 \\
\hline
\end{tabular}

${ }^{a}$ Values are given as mean and standard deviation, in parentheses, of three replicates. ${ }^{b}$ Abbreviations: LH, liquid infant food with honey; ND, not detected (below the limit of quantitation (LOQ $=0.01 \mathrm{~g} / 100 \mathrm{~g}$ of lipids)); SFA, saturated fatty acids; MUFA, monounsaturated fatty acids; PUFA, polyunsaturated fatty acids; TFA, trans fatty acids. ${ }^{c} \Sigma \mathrm{C} 16: 1$ is the sum of $c 7 \mathrm{C} 16: 1$ and $c 9 \mathrm{C} 16: 1 .{ }^{d} \Sigma \mathrm{C} 18: 1 t$ is the sum of all positional trans isomers of oleic acid (t4 C18:1-t16 C18:1). ${ }^{e} \mathrm{C} 18$ : $1 c 9$ is the oleic acid. ${ }^{f} \mathrm{C} 18: 1 \mathrm{c} 11$ is the cis-vaccenic acid. ${ }^{g} \Sigma \mathrm{C} 18: 2 t$ is the sum of the positional trans isomers of linoleic acid $(c 9, t 12 \mathrm{C18:2;} c 9, t 13 \mathrm{C18:2;} t 8, c 12$ C18:2; t9,t12 C18:2; $19, C 12 \mathrm{C} 18: 2) .{ }^{h} \mathrm{C} 18: 2$ is the linoleic acid. ${ }^{i} \Sigma \mathrm{C} 18: 3 t$ is the sum of the positional trans isomers of linolenic acid $(c 9, c 12, t 15 C 18: 3 ; c 9, t 12, c 15$ C18:3; $19, c 12, t 15 \mathrm{C} 18: 3 ; 19, c 12, c 15 \mathrm{C} 18: 3) .{ }^{j} \mathrm{C} 18: 3$ is the linolenic acid.

FA (C4-C8) probably derive from skimmed milk. The high oleic acid content (35.6 g/100 g lipids), as well as the relatively limited amount of linoleic acid (18.9 g/100 g lipids), may correspond to the addition of high-oleic sunflower oil as ingredient; this can be further confirmed by the occurrence of 7-stigmastenol, which is characteristic of this type of vegetable oil. Such level of linoleic acid, nevertheless, could also be attributed to soybean and rapeseed oils. On the other hand, the presence of large amounts of saturated FA (mainly palmitic, lauric, and myristic acids) could be ascribable to palm oil or palm olein (high in palmitic acid) and to coconut or palm kernel oil (high in lauric and myristic acids).

Trans isomers of C16:1 and C18:1 (mainly vaccenic acid) were found at concentrations of 0.03 and $0.17 \mathrm{~g} / 100 \mathrm{~g}$ of lipids, respectively, which can be considered within the usual TFA concentration range for refined, nonhydrogenated fats.

Although total TFA content is relatively low ( $0.2 \mathrm{~g}$ TFA/ $100 \mathrm{~g}$ lipids), their occurrence should be taken into account since TFA can be absorbed, metabolized, and incorporated into blood
Table 2. Main Sterols (mg/100 g of Product) Found in LH and LF Samples $^{a}$

\begin{tabular}{lcc}
\hline \multicolumn{1}{c}{ sterol } & $\mathrm{mg} / 100 \mathrm{~g}$ of LH sample & $\mathrm{mg} / 100 \mathrm{~g}$ of LF sample \\
\hline cholesterol & $1.34(0.13)$ & $1.31(0.10)$ \\
brassicasterol & $0.18(0.02)$ & $0.17(0.02)$ \\
campesterol & $1.18(0.09)$ & $1.16(0.07)$ \\
stigmasterol & $0.37(0.05)$ & $0.35(0.04)$ \\
$\beta$-sitosterol & $3.47(0.37)$ & $3.37(0.31)$ \\
total phytosterols & $5.20(0.53)$ & $5.06(0.44)$ \\
total sterols & $6.54(0.66)$ & $6.37(0.54)$
\end{tabular}

\footnotetext{
${ }^{a}$ Values are given as mean and standard deviation, between parentheses, of three replicates. $L O Q=0.1 \mathrm{mg} / 100 \mathrm{~g}$ of sample.
}

and tissue lipids by unweaning babies, according to the European Society for Pediatric Gastroenterology, Hepatology, and Nutrition (ESPGHAN) (27). TFA have been suggested to exhibit potential adverse effects on fetal and infant growth and development, possibly through inhibition of desaturation of the parent $n-6$ and $n-3$ fatty acids, linoleic acid and $\alpha$-linolenic acid, respectively, to their respective long-chain polyunsaturated fatty acids metabolites (28). A recent EC Directive states that TFA content in infant formulas shall not exceed $3 \%$ of the total fat content (26); however, no regulations have been published about TFA content in other baby foods yet (29).

Table 2 shows the sterol composition of the analyzed infant foods. $\beta$-Sitosterol was the most representative sterol (3.37 and $3.47 \mathrm{mg} / 100 \mathrm{~g}$ of $\mathrm{LF}$ and $\mathrm{LH}$, respectively) followed by cholesterol (1.31 and $1.34 \mathrm{mg} / 100 \mathrm{~g}$ of LF and LH, respectively) and campesterol (1.16 and $1.18 \mathrm{mg} / 100 \mathrm{~g}$ of $\mathrm{LF}$ and LH, respectively). Stigmasterol and brassicasterol were the less abundant sterols $(0.36$ and $0.18 \mathrm{mg} / 100 \mathrm{~g}$, respectively); the latter might derive from rapeseed oil added as vegetable oil in the product formulation. Cholesterol occurrence may be attributed to skimmed milk and palm or palm-kernel oil (up to $7 \%$ cholesterol, referred to total sterol content, in these oils) (30), as deduced from the FA composition.

Table 3 reports the amount of sterol oxides found in readyto-eat infant foods during storage. The total amount of SOP ranged from 81.1 to $97.8 \mu \mathrm{g} / 100 \mathrm{~g}$ in $\mathrm{LH}$ and from 77.5 to $96.1 \mu \mathrm{g} / 100 \mathrm{~g}$ in LF. Brassicasterol oxides were not analyzed in these samples.

The main SOP found was 7-ketositosterol, followed by the coeluting pair $\alpha$-epoxysitosterol + stigmastanetriol and cholestanetriol. Other SOP were detected at trace levels by GC-MS: 25-hydroxycholesterol, $7 \beta$-hydroxycampestanol (tentative), 5-hydroxy- $\beta$-sitosterol, $7 \beta$-hydroxysitostanol (tentative), and 6-keto$\beta$-sitosterol. Among these SOP, only the latter was quantifiable and ranged from 2.2 to $2.8 \mu \mathrm{g} / 100 \mathrm{~g}$ of sample.

$\beta$-Epoxycholesterol coeluted with minor amounts of stigmasterol that were not completely separated by the SPE cartridge, so a correction factor was calculated. This amount of stigmasterol was estimated in the SOP fraction of each sample as a relative percentage of the amount of cholesterol. Preliminary tests were run to verify that the stigmasterol/cholesterol ratio in the SPE fractions of SOP, remained constant. Because about $5.7 \%$ of the cholesterol peak area in the SOP fraction corresponded to the coeluting stigmasterol, this area was subtracted from the area of $\beta$-epoxycholesterol.

The type and total amount of SOP were similar in both types of infant food, regardless of the flavor ingredients (fruit and honey). No significant differences $(p<0.05)$ in the single SOP content were found with respect to storage time and type of sample, except for $\alpha$-epoxycampesterol and sitostanetriol. However, no clear trends were observed with respect to these factors. 
Table 3. Amount of SOP ( $\mu \mathrm{g} / 100 \mathrm{~g}$ of Sample) and Sterol Oxidation Rates (SOP/Sterol in Percentages) Found in Ready-to-Eat Infant Food (LH and LF Samples) During Storage ${ }^{a}$

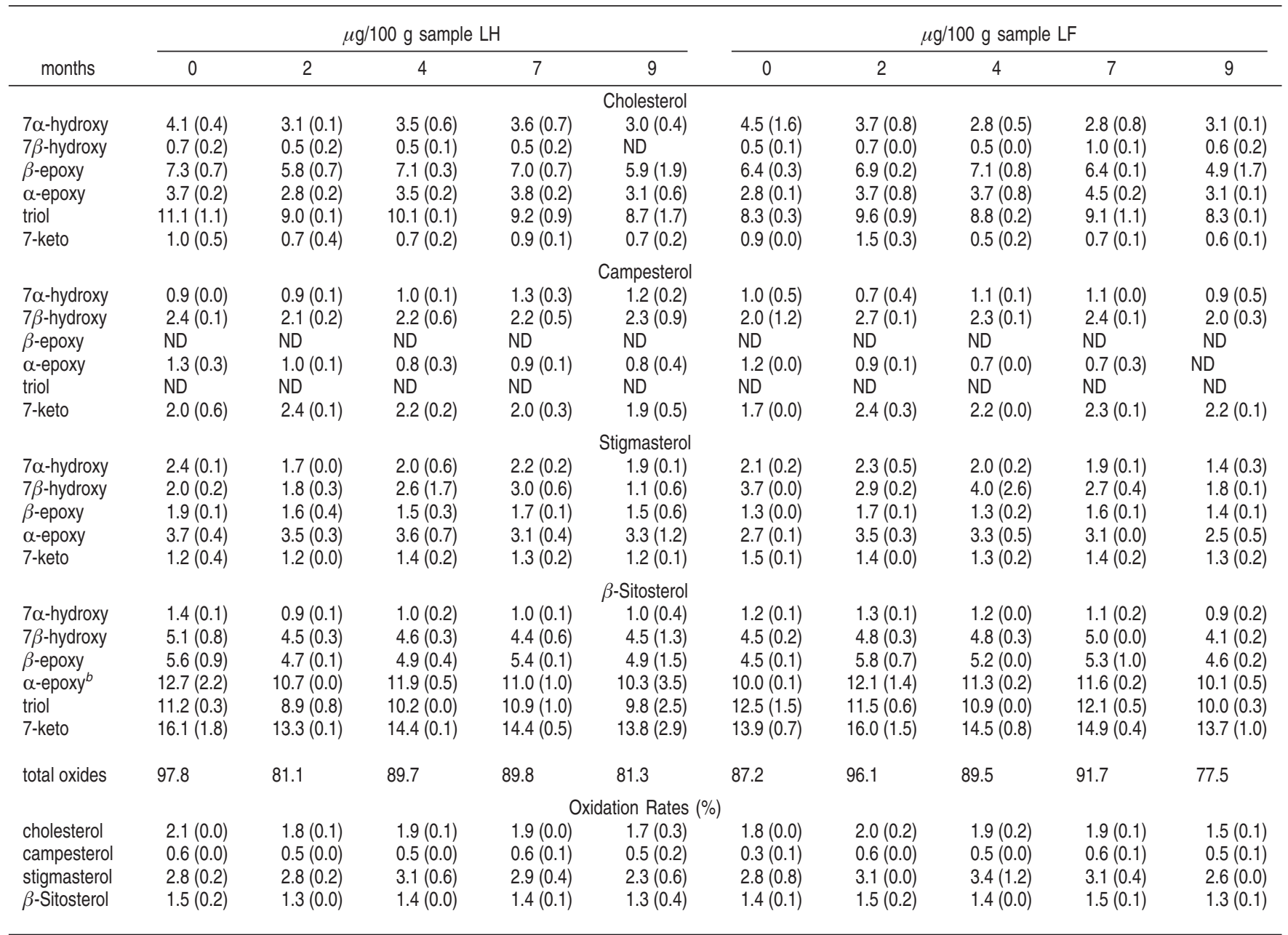

${ }^{a}$ Values are given as mean and standard deviation, between parentheses, of three replicates. ND, not detected (below the limit of quantitation (LOQ $=0.5 \mu \mathrm{g} / 100 \mathrm{~g}$ of sample)). ${ }^{b} \alpha$-Epoxysitosterol + stigmastanetriol.

Although 7-keto derivatives of sterols have been previously used as reliable markers of the extent of sterol oxidation in foods $(11,19,31)$, their formation may vary depending on the type of food matrices as well as their corresponding oxidation phase/status (32). In fact, the large quantitative differences found between 7-ketositosterol (mean value: $14.5 \mu \mathrm{g} / 100 \mathrm{~g}$ of sample) and 7-ketocholesterol (mean value: $0.8 \mu \mathrm{g} / 100 \mathrm{~g}$ ) might be due to diverse initial levels of sterol oxidation of the raw materials (milk and vegetable oils), as well as to the processing technologies and conditions used for their production. Vegetable oils are usually subjected to refining, which leads to the formation of different types and amounts of SOP, depending on the initial sterol content, on the chemical structure of the sterol oxides (already present and generated), and on the refining process applied to the oils (9). On the other hand, milk, the other main ingredient, is also subjected to different processes during manufacturing, such as pasteurization and spray-drying steps, which have been reported to cause sterol oxidation in milk cereals, infant formulas, and powdered milks $(6,17,18)$. All these events may have led to different oxidation stages in vegetable oils and milk fat.

The very low amounts of SOP found in these infant foods should not represent a health risk, because negative biological effects of SOP seem to manifest at relatively high concentrations in comparison with the daily intake that these foods would represent $(4,15,33)$.
7-Ketositosterol and 7-ketocholesterol detected in ready-toeat infant foods here analyzed are apparently much lower than those found in a previous study on powdered infant milk cereals (6). Zunin et al. reported that 7-ketositosterol and 7-ketocholesterol contents varied from 5.9 to $49.0 \mu \mathrm{g} / 100 \mathrm{~g}$ of sample and from 3.3 to $42.1 \mu \mathrm{g} / 100 \mathrm{~g}$ of sample, respectively. However, the powdered samples require water addition (about $19 \mathrm{~g}$ of product/100 $\mathrm{mL}$ of water) before consumption, which would result in a dilution of 7-ketositosterol and 7-ketocholesterol concentrations (1.1-9.3 and $0.6-8 \mu \mathrm{g} / 100 \mathrm{~g}$ of reconstituted product, respectively). Considering the reconstituted samples, their 7-ketositosterol content was about 3 times lower than those found in the infant foods here analyzed, even though $\beta$-sitosterol contents of both reconstituted and ready-to-eat samples were similar. On the other hand, reconstituted samples exhibited 7-ketocholesterol levels about 4 times higher than those detected in this study, due to their higher cholesterol content. $\beta$-Sitosterol and cholesterol displayed similar oxidation levels in powdered samples, whereas 7-ketositosterol was significantly higher in ready-to-eat infant foods. The greater extent of $\beta$-sitosterol oxidation in the samples here analyzed evinces that the ingredients from vegetable origin had a higher degree of oxidation, probably due to the quality of the raw materials and/ or processing conditions.

Table 3 also reports the single sterol oxidation rates (OR) found for ready-to-eat infant foods. No significant differences 


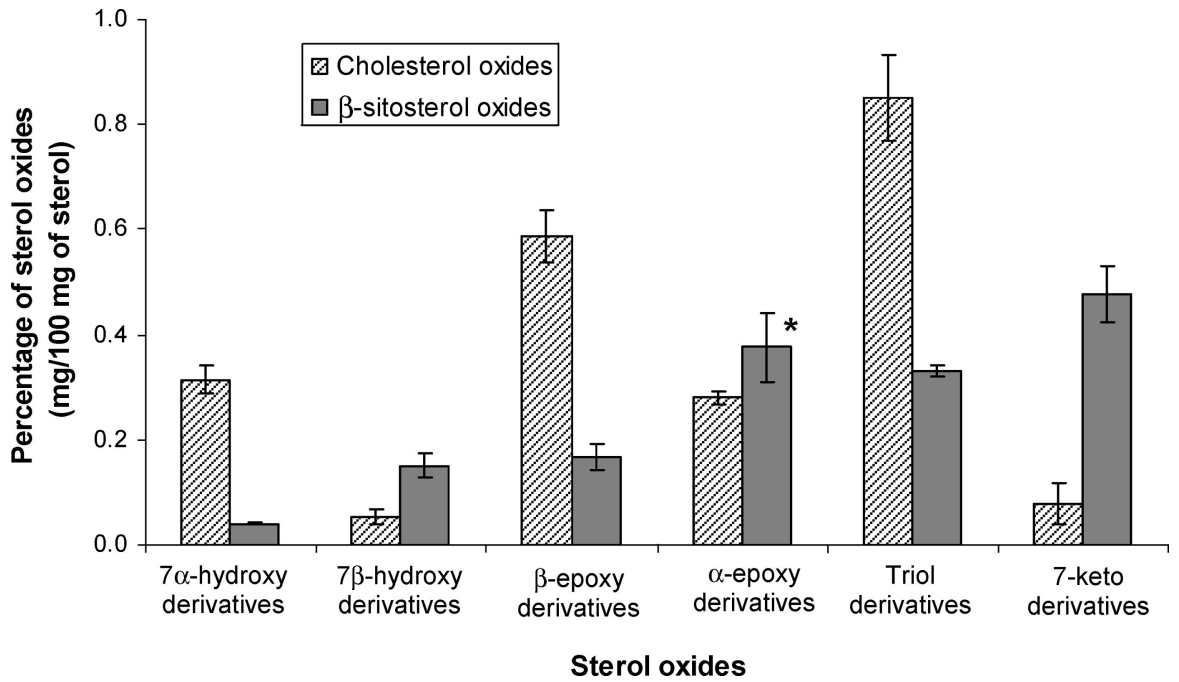

Figure 1. Relative percentages of $\beta$-sitosterol and cholesterol oxides (expressed with respect to the corresponding unreacted sterol) found in the liquid infant food with honey $(\mathrm{LH})$ sample at 0 months of storage. Data points represent means $(n=3) \pm$ standard deviations (some error bars may lay within the data points). The relative amount of $\alpha$-epoxysitosterol $\left({ }^{*}\right)$ would likely be overestimated, because of its overlapping with an unknown amount of stigmastanetriol under the analytical conditions used.

were found among the sterol OR of LH and LF, and no particular OR trend was observed with respect to storage. In both types of samples, stigmasterol had the highest OR (2.4-3.4\%), followed by cholesterol (1.5-2.1\%) and $\beta$-sitosterol $(1.3-1.5 \%)$. Because of its scarce presence, stigmasterol OR might be more influenced by analytical errors, thus leading to a relatively higher OR with respect to those of the other sterols. These remarkable differences might be caused by the different processing technologies applied to milk and vegetable oils, as well as to the diverse sterol susceptibility to oxidation. Because ready-to-eat infant foods are oil-in-water emulsions, oxidation likely occurs at the emulsion droplet interface. In fact, phytosterols are surface active, so they could be particularly prone to oxidation (34); this susceptibility also depends on the sterol relative concentrations at the oil-water interface.

If only 7-keto derivates are considered, cholesterol OR is drastically reduced to $0.05-0.08 \%$ and $0.04-0.11 \%$ in LH and $\mathrm{LF}$, respectively, whereas $\beta$-sitosterol OR decreases to $0.41-0.48 \%$ in both types of samples. Zunin et al. (6) reported $0.02-0.62 \%$ and $0.08-0.46 \%$ of cholesterol and $\beta$-sitosterol OR in powdered infant milk cereals, respectively, which further confirms the higher extent of oxidation of raw materials from vegetable origin used in the samples here analyzed.

Figure 1 compares the percentages of $\beta$-sitosterol and cholesterol oxides (expressed with respect to the corresponding unreacted sterol), detected in LH sample at 0 months of storage. Because sterol oxides remain roughly constant during storage in both LH and LF, data reported in Figure 1 are representative of sterol oxide percentages (\% $\mathrm{SO}$ ) in these infant foods; sterol oxide percentages at the beginning of the storage may provide a better picture of the original sterol oxidation level in the raw materials utilized for these products. Figure 1 shows that the percentages of the single $\beta$-sitosterol oxides are significantly different from those of the corresponding cholesterol oxides. In fact, the ratios between the relative amount of the $7 \alpha-/ 7 \beta$ hydroxy derivatives of cholesterol and $\beta$-sitosterol were 5.99 and 0.27 , respectively. The majority of 5,6-epoxy derivatives of cholesterol were present in their $\beta$ configuration, whereas those of $\beta$-sitosterol were mostly present as $\alpha$-epoxy; this influenced the $\beta$-/ $\alpha$-epoxy derivatives ratios, which were equal to 0.44 and 2.07 for $\beta$-sitosterol and cholesterol, respectively. It must be pointed out that the $\% \mathrm{SO}$ of $\alpha$-epoxysitosterol would likely be overestimated, because of its overlapping with an unknown amount of stigmastanetriol under the analytical conditions here used. The percentages of $\beta$-sitosterol and cholesterol triol derivatives were equal to $0.33 \%$ and $0.85 \%$, respectively. As aforementioned, the large difference between the relative amounts of 7-keto derivatives of $\beta$-sitosterol and cholesterol further confirms their diverse stage of oxidation. Besides the 7-keto derivatives, the other $\beta$-sitosterol oxides seem to have reached the most stable forms from the thermodynamics standpoint (1), that is, $7 \beta$-hydroxy and $\alpha$-epoxy rather than $7 \alpha$ hydroxy and $\beta$-epoxy derivatives; however, cholesterol exhibits the opposite trend. Furthermore, the sums of the relative amounts of $7 \alpha$-hydroxy, $7 \beta$-hydroxy, and 7-keto derivatives were 20.6 and $43.3 \%$ for cholesterol and $\beta$-sitosterol, respectively, whereas the sums of $\alpha$-epoxy, $\beta$-epoxy, and triol derivatives of cholesterol and $\beta$-sitosterol were 79.4 and $56.7 \%$, respectively. Considering that 7-hydroxy and 7-keto compounds are generated by a different oxidation pathway than epoxy and triol derivatives (1), these results confirm the diverse oxidation stage and origin of cholesterol and $\beta$-sitosterol in samples here analyzed. Formation of relevant amounts of epoxy derivatives might be partly due to the interaction of sterols with hydrogen peroxide, which is released by microbial enzymes naturally present in milk (35). Under these environmental conditions, epoxide hydrolysis into triols would likely be unavoidable.

The low sterol oxidation level observed in these ready-toeat infant foods might be attributed to the effectiveness of the packaging system (inert atmosphere), to the slight enrichment with vitamins having antioxidant properties (vitamins $\mathrm{A}, \mathrm{C}$ and E), and to the presence of Maillard reaction products (MRP) found in these samples (36).

The antioxidant capacity of MRP $(37,38)$ might have prevented sterols from oxidizing during storage, thus maintaining the same oxidative status reached after processing. In addition, the physical state (liquid) of the milk-cereal-based infant foods could have also favored MRP solubilization, thus contributing to the product stability (39).

In conclusion, this study evidences a low sterol oxidation level in ready-to-eat infant foods, which remains roughly constant during storage. However, the actual presence of such compounds confirms the need of monitoring SOP in this type of food products, because of their potential negative health effects. To 
ensure the best nutritional and safety characteristics in infant foods, special attention should be devoted to the choice of the raw materials (in particular oil) and the processing conditions and technologies, which seem to greatly influence SOP formation and accumulation in such products.

\section{ABBREVIATIONS USED}

COP, cholesterol oxidation products; FA, fatty acids; GCFID, gas chromatograph-flame ionization detector; GC-MS, gas chromatograph-mass spectrometry; IS, internal standard; LF, liquid infant food with fruits; LH, liquid infant food with honey; MRP, maillard reaction products; MUFA, monounsaturated fatty acids; OR, oxidation rate; $\mathrm{POP}$, phytosterol oxidation products; PUFA, polyunsaturated fatty acids; SFA, saturated fatty acids; SOP, sterol oxidation products; SPE, solid-phase extraction; TFA, trans fatty acids.

\section{ACKNOWLEDGMENT}

The authors thank Mara Mandrioli, University of Bologna, for the technical support and assistance during sample analysis. The authors thank Hero España S.A. for providing the samples.

This work was financially supported by Hero España S.A. through a grant and by the Generalitat Valenciana through the Bionutest group (03/003).

\section{LITERATURE CITED}

(1) Smith, L. L. Cholesterol Autoxidation; Plenum Press: New York, 1981.

(2) Guardiola, F.; Bou, R.; Boatella, J.; Codony, R. Analysis of sterol oxidation products in foods. J. AOAC Int. 2004, 87, 441-466.

(3) Garcia-Cruset, S.; Carpenter, K. L. H.; Codony, R.; Guardiola, F. Cholesterol Oxidation Products and Atherosclerosis. In Cholesterol and Phytosterol Oxidation Products: Analysis, Occurrence, and Biological Effects; Guardiola, F., Dutta, P. C., Codony, R., Savage, G. P., Eds.; AOCS Press: Champaign, Illinois, 2002; pp 241-277.

(4) Schroepfer, G. J., Jr. Oxysterols: Modulators of cholesterol metabolism and other processes. Physiol. Rev. 2000, 80, 361554.

(5) Osada, K. Cholesterol oxidation products: other biological effects. In Cholesterol and Phytosterol Oxidation Products: Analysis, Occurrence, and Biological Effects; Guardiola, F., Dutta, P. C., Codony, R., Savage, G. P., Eds.; AOCS Press: Champaign, Illinois, 2002; pp 278-318.

(6) Zunin, P.; Calcagno, C.; Evangelisti, F. Sterol oxidation in infant milk formulas and milk cereals. J. Dairy Res. 1998, 65, 591598.

(7) Dutta, P. C. Determination of phytosterol oxidation products in foods and biological samples. In Cholesterol and Phytosterol Oxidation Products: Analysis, Occurrence, and Biological Effects; Guardiola, F., Dutta, P. C., Codony, R., Savage, G. P., Eds.; AOCS Press: Champaign, Illinois, 2002; pp 335-374.

(8) Dutta, P. C.; Savage, G. P. Formation and Content of Phytosterol Oxidation Products in Foods. In Cholesterol and Phytosterol Oxidation Products: Analysis, Occurrence, and Biological Effects; Guardiola, F., Dutta, P. C., Codony, R., Savage, G. P., Eds.; AOCS Press: Champaign, Illinois, 2002; pp 319-334.

(9) Bortolomeazzi, R.; Cordano, F.; Pizzale, L.; Conte, L. S. Presence of phytosterol oxides in crude vegetables oils and their fate during refining. J. Agric. Food Chem. 2003, 51, 2394-2401.

(10) Conchillo, A.; Cercaci, L.; Ansorena, D.; Rodriguez-Estrada, M. T.; Lercker, G.; Astiasarán, I. Levels of phytosterol oxides in enriched and nonenriched spreads: application of a thin-layer chromatography-gas chromatography methodology. J. Agric. Food Chem. 2005, 53, 7844-7850.
(11) Cercaci, L.; Conchillo, A.; Rodriguez-Estrada, M. T.; Ansorena, D.; Astiasarán, I.; Lercker, G. Preliminary study on health-related lipid components of bakery products. J. Food Protect. 2006, 69, 1393-1401.

(12) Normén, L.; Frohlich, J.; Trautwein, E. Role of plant sterols in cholesterol lowering. In Phytosterols as Functional Food Components and Nutraceuticals, 1st ed.; Dutta, P. C., Ed.; Marcel Dekker Inc.: New York, 2004; pp 243-315.

(13) Grandgirard, A.; Martine, L.; Demaison, L.; Cordelet, C.; Joffre, C.; Berdeaux, O.; Semon, E. Oxyphytosterols are present in plasma of healthy human subjects. Br. J. Nutr. 2004, 91, 101106.

(14) Lea, L. J.; Hepburn, P. A.; Wolfreys, A. M.; Baldrick, P. Safety evaluation of phytosterol esters. Part 8. Lack of genotoxicity and subchronic toxicity with phytosterol oxides. Food Chem. Toxicol. 2004, 42, 771-783.

(15) Ryan, E.; Chopra, J.; McCarthy, F.; Maguire, A. R.; O’Brien, N. M. Qualitative and quantitative comparison of the cytotoxic and apoptotic potential of phytosterol oxidation products with their corresponding cholesterol oxidation products. Br. J. Nutr. 2005, 94, 443-451.

(16) Abramsson-Zetterberg, L.; Svensson, M.; Johnsson, L. No evidence of genotoxic effect in vivo of the phytosterol oxidation products triols and epoxides. Toxicol. Lett. 2007, 173, 132-139.

(17) Angulo, A. J.; Romera, J. M.; Ramirez, M.; Gil, A. Effects of storage conditions on lipid oxidation in infant formulas based on several protein sources. J. Am. Oil Chem. Soc. 1998, 75, 16031607.

(18) Przygonski, K.; Jelen, H.; Wasowicz, E. Determination of cholesterol oxidation products in milk powder and infant formulas by gas chromatography and mass spectrometry. Nahrung $\mathbf{2 0 0 0}$, $44,122-125$.

(19) Scopesi, F.; Zunin, P.; Mazzella, M.; Testa, M.; Boggia, R.; Evangelisti, F.; Serra, G. 7-ketocholesterol in human and adapted milk formulas. Clin. Nutr. 2002, 21, 379-384.

(20) Evangelisti, F.; Zunin, P.; Boggia, R.; Calcagno, C. Cholesterol oxidation in meat-based baby foods. J. AOAC Int. 2004, 87, 505510.

(21) Zunin, P.; Salvadeo, P.; Boggia, R.; Evangelisti, F. Sterol oxidation in meat- and fish-based homogenized baby foods containing vegetable oils. J. AOAC Int. 2006, 89, 441-446.

(22) Boselli, E.; Velazco, V.; Caboni, M. F.; Lercker, G. Pressurized liquid extraction of lipids for the determination of oxysterols in egg-containing food. J. Chromatogr. A 2001, 917, 239-244.

(23) Folch, J.; Lees, M.; Sloane-Stanley, G. H. A simple method for the isolation and purification of total lipids from animal tissues. J. Biol. Chem. 1957, 226, 497-509.

(24) Sweeley, C. C.; Bentley, R.; Makita, M.; Wells, W. W. Gas-liquid chromatography of trimethylsilyl derivatives of sugars and related substances. J. Am. Oil Chem. Soc. 1963, 85, 2497-2507.

(25) Guardiola, F.; Codony, R.; Rafecas, M.; Boatella, J. Comparison of three methods for the determination of oxysterols in spraydried egg. J. Chromatogr. A 1995, 705, 289-304.

(26) 2006/141/EC: European Commission Directive of 22 December 2006 on infant formulae and follow-on formulae and amending Directive 1999/21/EC. Off J. Eur. Union 2006, 401, 1-33.

(27) Aggett, P. J.; Haschke, F.; Heine, W.; Hernell, O.; Koletzko, B.; Launiala, K.; Rey, J.; Rubino, A.; Schöch, G.; Senterre, J.; Tormo, R. ESPGHAN (European Society for Pediatric Gastroenterology, Hepatology and Nutrition) Committee on Nutrition: Comment on the content and composition of lipids in infant formulas. Acta Paediatr. Scand. 1991, 80, 887-896.

(28) Decsi, T.; Burus, I.; Molnar, S.; Minda, H.; Veitl, V. Inverse association between trans isomeric and long-chain polyunsaturated fatty acids in cord blood lipids of full-term infants. Am. J. Clin. Nutr. 2001, 74, 364-368.

(29) 2006/125/EC: European Commission Directive of 5 December 2006 on processed cereal-based foods and baby foods for infants and young children. Off J. Eur. Union 2006, 339, 16-35. 
(30) Kamm, W.; Dionisi, F.; Hischenhuber, C.; Engel, K. H. Authenticity assessment of fats and oils. Food Rev. Int. 2001, 17, 249290.

(31) Lercker, G.; Rodriguez-Estrada, M. T. Cholesterol oxidation: presence of 7-ketocholesterol in different food products. J. Food Comp. Anal. 2000, 13, 625-631.

(32) Kemmo, S.; Soupas, L.; Lampi, A.-M.; Piironen, V. Formation and decomposition of stigmasterol hydroperoxydes and secondary oxidation products during thermo-oxidation. Eur. J. Lipid Sci. Technol. 2005, 107, 805-814.

(33) Sevanian A. Personal communication. In The International Symposium "Biological Free Radical Oxidations and Antioxidants”; Ursini, F., Cadenas, E., Eds.; CLUEB University Publisher Udine: Padova, Italy, 1991; Vol. 1-4.

(34) Cercaci, L.; Rodriguez-Estrada, M. T.; Lercker, G.; Decker, E. A. Phytosterol oxidation in oil-in-water emulsion and bulk oil. Food Chem. 2007, 102, 66-76.

(35) Lewis, M. J. Improvements in the Pasteurization and Sterilization of Milk. In Dairy Processing: Improving Quality; Smit, G. Ed.,
Woodhead Publishing Limited: Cambridge, England, 2003; Ebook.

(36) Bosch, L.; Alegría, A.; Farré, R.; Clemente, G. Fluorescence and color as markers for the Maillard reaction in milk-cereal based infant foods during storage. Food Chem. 2007, 105, 1135-1143.

(37) Alaiz, M.; Hidalgo, F. J.; Zamora, R. Antioxidative activity of nonenzymatically browned proteins produced in oxidized lipid/ protein reactions. J. Agric. Food Chem. 1997, 45, 1365-1369.

(38) Ames, J. M. Melanoidins as pro- or antioxidants. Cerevisia 2001, 26, 210-216.

(39) García-Llatas, G.; Lagarda, M. J.; Clemente, G.; Farré, R. Monitoring of headspace volatiles in milk-cereal-based liquid infant foods during storage. Eur. J. Lipid Sci. Technol. 2006, 108, 1028-1036.

Received for review August 17, 2007. Revised manuscript received November 6, 2007. Accepted November 8, 2007.

JF072475G 